\title{
Preparation of Polyoxetane Resins Having Polyoxirane Segments in the Pendant and Cross-Linking Chains and Uses as Polymeric Solvents for Alkali-Metal Ions
}

\author{
Akihiko Ueyama, ${ }^{*}$ Michiko Mizuno, Shigeyoshi KanoH, and Masatoshi Motoi \\ Department of Chemistry and Chemical Engineering, Faculty of Engineering, Kanazawa University, \\ 2-40-20 Kodatsuno, Kanazawa 920-8667, Japan \\ *New Materials Development Department, Industrial Technology Center of Fukui Prefecture, \\ 61 Kawaiwashizuka, Fukui 910-0102, Japan
}

(Received August 27, 2002; Accepted October 26, 2002)

\begin{abstract}
Several polyoxirane-polyoxetane composite resins were prepared by $\mathrm{BF}_{3}$-initiated cationic polymerizatons of $\alpha$-mono- and $\alpha, \omega$-dioxetanyl-substituted polyoxiranes with an ordinary bisoxetane or without adding it at $0{ }^{\circ} \mathrm{C}$ for $50 \mathrm{~h}$. The resins obtained were examined as a phase-transfer catalyst in organic reactions, such as halogen-exchange, Williamson-type etherification, alkene-forming elimination, and C-alkylation of malonic esters, using $\mathrm{NaI}, \mathrm{KI}, \mathrm{NaOH}$, or $\mathrm{KOH}$ as a source of a nucleophile or a base. Thus, it was indicated that the pendant and cross-linking polyoxirane segments acted as polymeric solvents capable of catching sodium and potassium cations in the manner of cooperative coordination. Herein, polyether matrices may play an important role in forming reaction stages, possibly due to selfassembled oxyethylene segments and due to moderately flexible polyoxetane backbones.
\end{abstract}

KEY WORDS Cationic Ring-Opening Polymerization / Polyoxetanes / Polyoxiranes / Polymer Solvent / Phase-Transfer Catalyst /

Investigation for the synthesis and uses of functional polymers based on polyoxetane backbones is very interesting to us, since the polyoxetane backbones have several properties desirable for supporting matrices of functional polymers, e.g., flexibility, thermal stability, base-resistance, and moderate polarity, and are easily obtained by cationic ring-opening polymerization of oxetane monomers. Furthermore, the polymerization are quite unsusceptible to polar functional groups involved in the side chain of the oxetane ring, and these groups are used as functioning species directly or after further chemical modification by an appropriate polymer reaction. ${ }^{1}$ For one of polyoxetanes with pendant functional groups, we recently reported that polyoxetane resins anchoring di- and tri(oxyethylene) side-chains, $\mathbf{R 3 a}(2 / l)$ and $\mathbf{R 3 a}(3 / l)$, were obtained by polymerization of the corresponding oxetanes, $\mathbf{3 a}(2)$ and $\mathbf{3 a}(3)$, with 1,4-bis(3-methyl-3-oxetanylmethoxy)butane (4) using a trifluoroborane-ether complex $\left(\mathrm{BF}_{3} \mathrm{OEt}_{2}\right)$ as an initiator in dichloromethane (DCM) at $0{ }^{\circ} \mathrm{C}$ (Schemes 1 and 2).

The pendant oligo(oxyethylene) chains anchored onto 4-cross-linked polyoxetane resins were polymeric media solvating alkali-metal cations, as confirmed from the results of a halogen-exchange reaction and an alkene-forming elimination reaction using the resins as a phase-transfer catalyst (PTC). ${ }^{2}$

It is known that the ether moieties of polyoxiranes

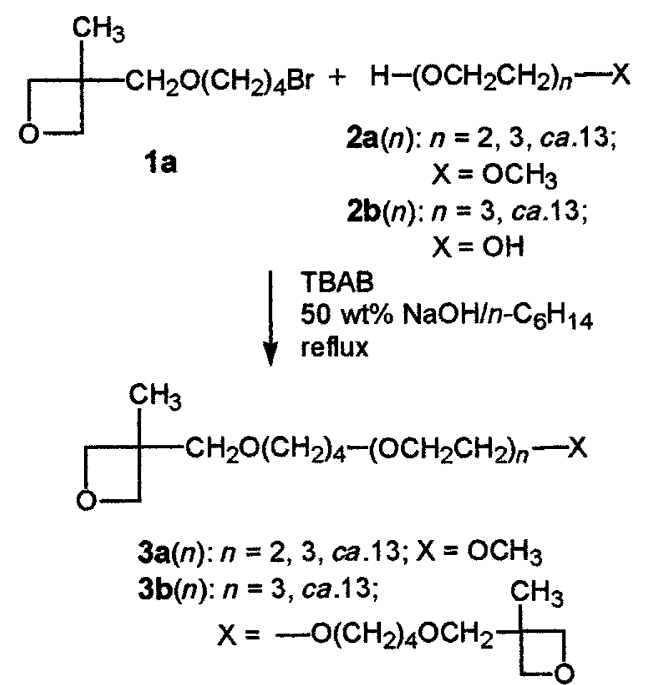

Scheme 1. Preparation of monomers, $3 \mathbf{a}(n)$ and $\mathbf{3 b}(n)$.

can also catch alkali-metal cations in a cooperative coordination manner similar to that of crown ethers and that the counteranions of such cations can act as a nucleophile or a base for several reaction types. ${ }^{3}$

From another point of view, polyoxiranes are regarded as important materials for an polymeric electrolyte of alkali-metal cations. In the material design, cross-linked or branched forms of polyoxirane chains are required to improve conductive efficiency upon cation-transferring, since polyoxirane chains give a crystalline state at a high concentration of alkali-metal cations, decreasing ion conductivity. 


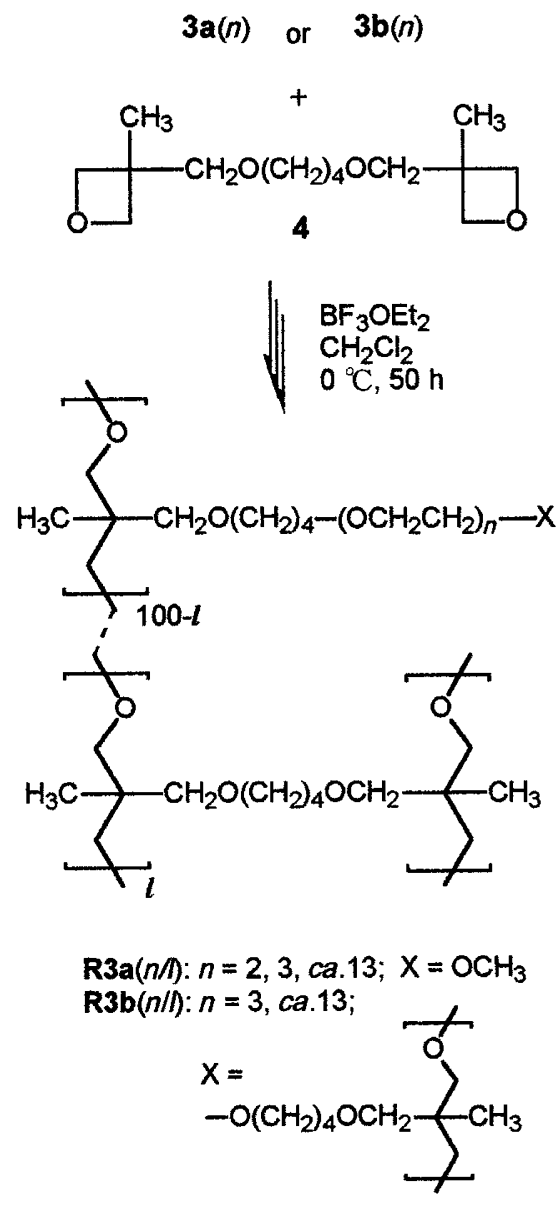

Scheme 2. Preparation of polyoxetane resins with the pendant and cross-linked oxyethylene units, $\mathbf{R 3} \mathbf{a}(n / l)$ and $\mathbf{R} \mathbf{3} \mathbf{b}(n / l)$.

Miwa et al. recently prepared $\alpha, \omega$-dioxetanyl-substituted polyoxiranes to convert them to polyoxiranepolyoxetane networks containing lithium cations abundantly by cationic ring-opening polymerizations using large amounts of several lithium salts as an initiator. ${ }^{4}$

Thus, a variety of polyoxirane networks will be designed to produce promising materials with ionaffinity. In this study, we prepared polyoxetane resins having oxyethylene units in the pendant and crosslinking chains, $\mathbf{R 3 a}(13 / l), \mathbf{R} 3 \mathbf{b}(3 / l)$, and $\mathbf{R 3} \mathbf{b}(13 / l)$, by cationic ring-opening polymerizations of the corresponding $\alpha$-mono- and $\alpha, \omega$-dioxetanyl-substituted triand poly(oxyethylene)s, 3a(13), 3b(3), and $\mathbf{3 b}(13)$, respectively, with 4 or without adding it, and examined these resins as polymeric media capable of solvating alkali-metal cations in several phase-transfer catalyzed organic reactions. These results serve for the characterization of the new type of polyoxirane-polyoxetane composite resins prepared in this work.

\section{RESULTS AND DISCUSSION}

\section{Preparation of Monomers and Polymers}

Mono- and dioxetanyl-substituted monomers, $\mathbf{3 a}(n)$

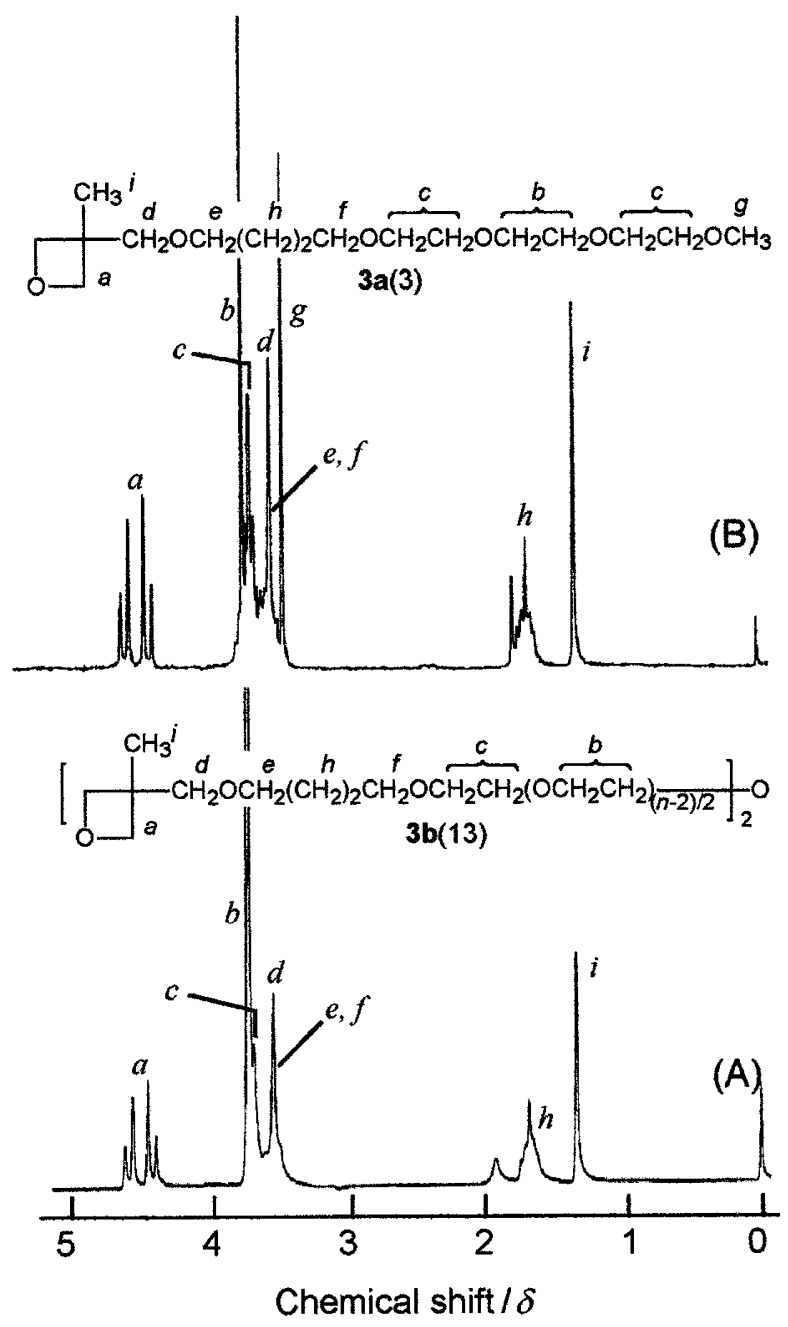

Figure 1. $100 \mathrm{MHz}{ }^{1} \mathrm{HNMR}$ spectra $\left(\mathrm{CDCI}_{3}\right)$ of monomers, (A) $\mathbf{3 b}(13)$ and (B) $\mathbf{3 a}(3)$.

and $3 \mathbf{b}(n), n=2,3$, or 13 , were obtained by phasetransfer catalytic reactions of the bromine atom of $1 \mathrm{a}$ with the terminal hydroxy groups of oligo- and poly(oxyethylene) glycols, $\mathbf{2 a}(n)$ and $\mathbf{2} \mathbf{b}(n)$. Oxetanes, $\mathbf{3 a}(13), \mathbf{3 b}(3)$, and $\mathbf{3 b}(13)$ as pot-residues, obtained after removing the solvent and volatile impurities from the reaction mixture under vacuum, were subjected directly to $\mathrm{BF}_{3}$-initiated cationic polymerization. The structures of the monomers obtained were confirmed by ${ }^{1} \mathrm{H}$ NMR spectroscopy. For instance, the ${ }^{1} \mathrm{H}$ NMR spectra of $\mathbf{3 b}(13)$ and $\mathbf{3 a}(3)$ are shown in Figure 1, where these signals are assignable to the corresponding protons of the desired products.

Oxetane monomers having poly(oxyethylene) chains in the form of pendant or cross-linking were polymerized with 4 or without it using 0.03 equiv. of a $\mathrm{BF}_{3} \mathrm{OEt}_{2}$ initiator in $\mathrm{DCM}$ at $0{ }^{\circ} \mathrm{C}$ for $50 \mathrm{~h}$. The formed gels were collected by filtration, washed with $20 \%$ aqueous methanol, and dried in a vacuum to give elastic products in good yield. As exemplified by Figure 2 for $\mathbf{3 b}(13)$ and $\mathbf{R} 3 \mathbf{b}(13 / 0)$, the IR spectra of the poly- 
Table I. A list of resins with oxyethylene segments ${ }^{\mathrm{a}}$

\begin{tabular}{|c|c|c|c|c|c|}
\hline \multirow{2}{*}{ Resin } & \multirow{2}{*}{$\begin{array}{l}\text { Monomers } \\
\text { in feed }\end{array}$} & \multicolumn{2}{|c|}{ Resin structure $^{b}$} & \multirow{2}{*}{$\frac{\text { Yield }^{\mathrm{c}}}{\%}$} & \multirow{2}{*}{$\frac{\mathrm{OEU}^{\mathrm{d}}}{\mathrm{mmol} \mathrm{g}^{-1}}$} \\
\hline & & $n$ & $l$ & & \\
\hline$\overline{\mathbf{R 3 a}(2 / 13)}$ & $\mathbf{3 a}(2) / \mathbf{4}$ & 2 & 13 & 90 & 6.64 \\
\hline R3a(3/13) & $3 \mathbf{a}(3) / 4$ & 3 & 13 & 92 & 9.04 \\
\hline $\mathbf{R 3 a}(3 / 30)$ & $3 \mathbf{a}(3) / 4$ & 3 & 30 & 85 & 6.91 \\
\hline $\mathbf{R 3 a}(13 / 0)$ & $\mathbf{3 a}(13)$ & 13 & 0 & 60 & 16.53 \\
\hline R3a(13/60) & $\mathbf{3 a}(13) / \mathbf{4}$ & 13 & 60 & 91 & 10.99 \\
\hline $\mathbf{R} 3 \mathbf{b}(3 / 0)$ & $\mathbf{3 b}(3)$ & 3 & 0 & 100 & 6.47 \\
\hline $\mathbf{R 3 b}(3 / 30)$ & $3 b(3) / 4$ & 3 & 30 & 98 & 5.23 \\
\hline $\mathbf{R 3 b}(13 / 0)$ & $\mathbf{3 b}(13)$ & 13 & 0 & 86 & 14.45 \\
\hline $\mathbf{R} 3 \mathbf{b}(13 / 13)$ & $3 b(13) / 4$ & 13 & 13 & 85 & 13.88 \\
\hline $\mathbf{R} 3 \mathbf{b}(13 / 30)$ & $3 b(13) / 4$ & 13 & 30 & 99 & 12.92 \\
\hline $\mathbf{R 3 b}(13 / 60)$ & $\mathbf{3 b}(13) / \mathbf{4}$ & 13 & 60 & 100 & 10.13 \\
\hline
\end{tabular}

${ }^{\mathrm{a}}$ Obtained by polymerization of monomers with a $\mathrm{BF}_{3} \mathrm{OEt}_{2}$ initiator in $\mathrm{DCM}$ at $0{ }^{\circ} \mathrm{C}$ for $50 \mathrm{~h}$. ${ }^{\mathrm{b}}$ See Scheme 2 for number of repeated oxyethylene unit, $n$, and mole fraction of a 4 unit, $l$.

${ }^{\mathrm{c}}$ Based on the total weight of charged monomers. ${ }^{\mathrm{d}}$ Amount of OEU per $1 \mathrm{~g}$ resin.

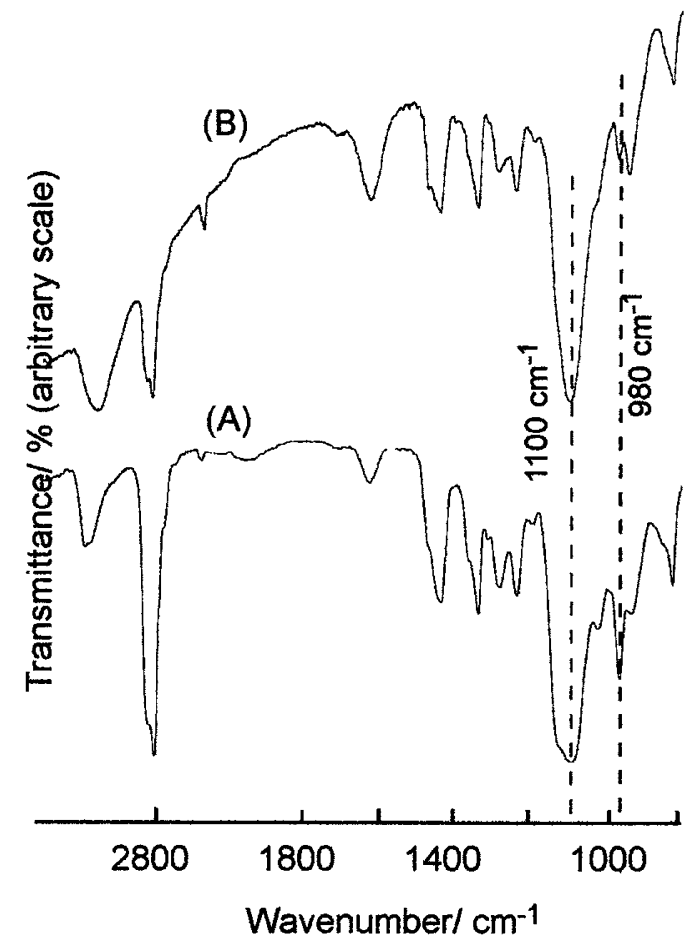

Figure 2. IR spectra of (A) $\mathbf{3 b}(13)$ (neat) and (B) $\mathbf{R} \mathbf{3 b}(13 / 0)$ ( $\mathrm{KBr}$ disk).

mer products showed a band due to the $\mathrm{C}-\mathrm{O}-\mathrm{C}$ stretching of the acyclic ether linkage at around $1100 \mathrm{~cm}^{-1}$ and a much weakened band at $980 \mathrm{~cm}^{-1}$ due to the $\mathrm{C}-\mathrm{O}-\mathrm{C}$ stretching of the oxetane ring, which was observed as a distinguished IR band in the spectra of the corresponding monomers. This indicates that a trace amount of the oxetane ring is left as a pendant residue in the polyether network, particularly for the ring-opening polymerization of oxetane rings linked with a long poly(oxyethylene) spacer, since the analogous resins obtained from $\mathbf{3 a}(2)$ and $\mathbf{3 a}(3)$ showed no IR band at $980 \mathrm{~cm}^{-1}$.

The amount of an oxyethylene unit (OEU, mmol
Table II. Elemental-analysis data for typical resins used in the present study

\begin{tabular}{llrrc}
\hline \multirow{2}{*}{ Resin } & \multicolumn{4}{c}{ Anal (\%) } \\
\cline { 2 - 5 } & \multicolumn{1}{c}{ C } & \multicolumn{1}{c}{$\mathrm{H}$} & $\mathrm{Br}$ \\
\hline $\mathbf{R 3 a}(2 / 13)$ & Calcd & 61.35 & 10.22 & 0.00 \\
& Found & 58.05 & 9.82 & 0.00 \\
$\mathbf{R 3 a}(3 / 13)$ & Calcd & 60.51 & 10.09 & 0.00 \\
& Found & 60.12 & 10.03 & 0.00 \\
$\mathbf{R 3 a}(13 / 60)$ & Calcd & 59.60 & 9.76 & 0.00 \\
& Found & 59.42 & 9.74 & 0.60 \\
$\mathbf{R 3 b}(13 / 0)$ & Calcd & 58.50 & 9.62 & 0.00 \\
& Found & 58.02 & 9.61 & 0.50 \\
\hline
\end{tabular}

$1 \mathrm{~g}^{-1}$ resin) was calculated from a mole ratio for charged monomers, since polymer yields were considerably high, and the elemental-analysis data determined for several of the polymeric products were close to the calculated values. For R3a(2/13), the $\mathbf{4}$ content calculated from the elemental-analysis data for carbon atom was $11-12 \mathrm{~mol} \%$. These results are summarized in Tables I and II.

Trace amounts of bromine atom were detected for $\mathbf{R 3 a}(13 / 60)$ and $\mathbf{R 3 b}(13 / 0)$, but not for R3a(2/13) and R3a(3/13). These bromine atoms seem to be derived from those of monomeric units of $\mathbf{1 a}$, not removed completely from the pot-residues under vacuum, although these bromine-containing units can be regarded as a negligible fraction. Thus, polyoxetanepolyoxrirane network resins were obtained in an easy procedure.

Uses of Polyoxetane-Polyoxrirane Network Resins as a PTC

Phase-transfer catalyzing ability of polyoxetanepolyoxirane resins were examined for halogenexchange (eq 1), Williamson-type etherification reaction (eqs 2 and 3), elimination of alkyl halides (eq 4), 

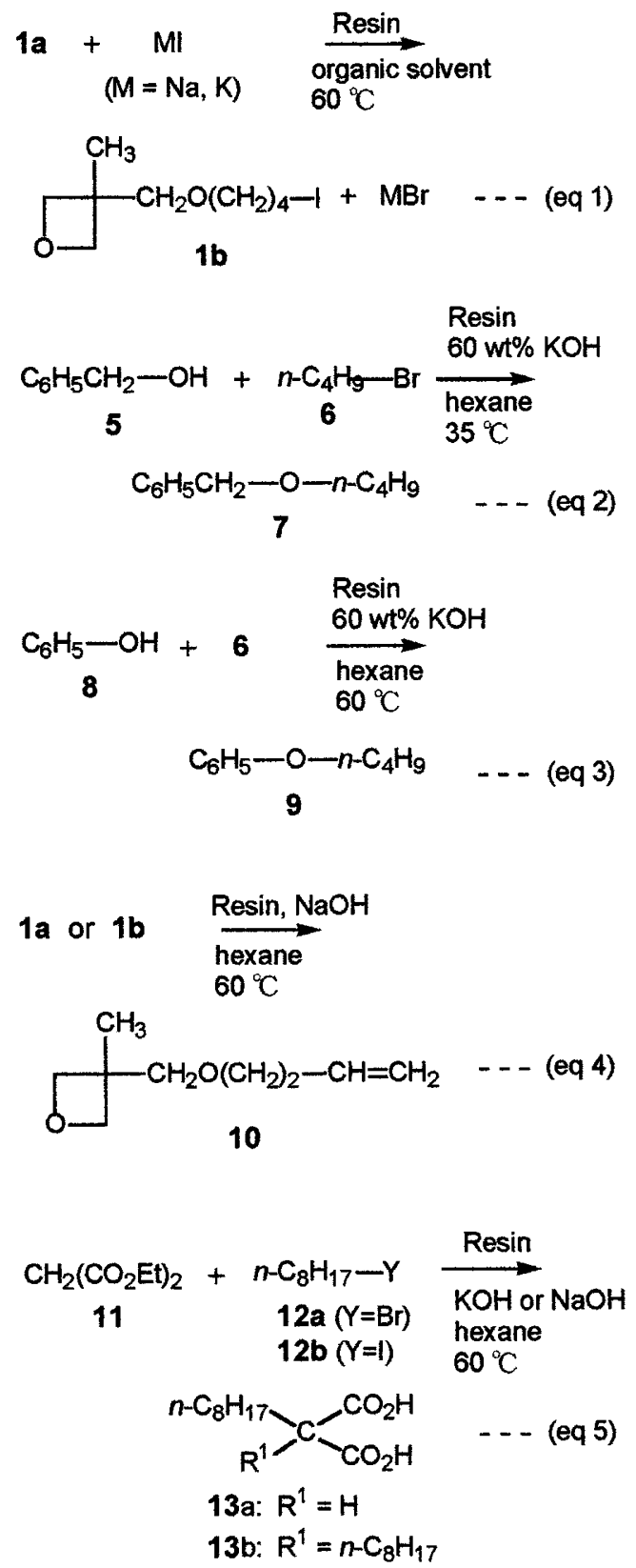

Scheme 3. Phase-transfer catalyzed organic reactions for ionexchange, Williamson-type etherification, alkene-forming elimination, and C-alkylation of diethyl malonate.

and C-alkylation of diethyl malonate (eq 5) (Scheme 3).

Halogen-Exchange Reaction. In this study, an oxetanyl-containing bromide, 1a, was used as a substrate, although octyl bromide (12a) was used in our previous paper, since the influence of an oxetane moiety, which is more polar and hydrophilic than an alkyl group, on the halogen-exchange reaction may be revealed. In Figure 3, the phase-transfer catalytic activities of resins are compared with each other by $\mathbf{1 b}$ yield-time curves in reactions between 1a and $\mathrm{NaI}$ in the presence of 1.5 equiv. OEU.

In the reactions of $\mathbf{1 a}$ using $\mathbf{R 3} \mathbf{a}(2 / 13)$ and R3a(3/13), the shorter di(oxyethylene) arms had somewhat lower catalytic activity than the longer ones (see

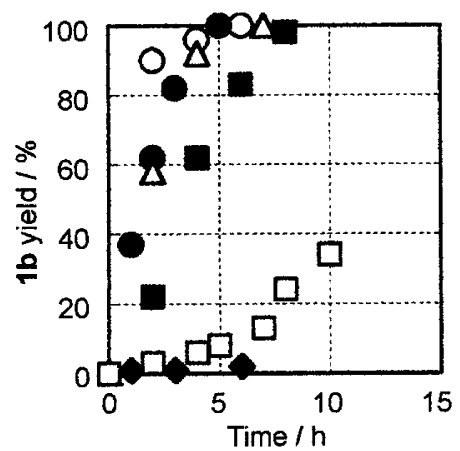

Figure 3. 1b yield-time curves for halogen-exchange reactions of 1a with 3 equiv. $\mathrm{NaI}$ using several resins (containing

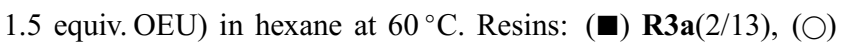
$\mathbf{R 3 a}(3 / 13),(\bullet) \mathbf{R 3 a}(3 / 30),(\triangle) \mathbf{R 3 a}(13 / 60),(\diamond)$ without resin, and () using 12a as a substrate in the presence of $\mathbf{R 3 a}(2 / 13)$.

plots with $\bigcirc$ and $\mathbf{\square}$ ), although $\mathbf{R 3 a}(2 / 13)$ converted 12a to the corresponding iodide in a much lower rate than R3a(3/13) (see plots with $\square$ and $\mathbf{\square}$ ), as shown in the previous report too. ${ }^{2}$ This indicates that $\mathbf{1 a}$ is taken in smoothly into the oxyethylene segments, since the oxetanyl moiety of 1a used in hexane has an affinity for oxyethylene segments. Additionally, as compared with the result obtained using the hexane solvent, a much lowered yield of $\mathbf{1 b}$ was observed in a 1,4-dioxane solvent, possibly due to solvation of oxyethylene segments with 1,4-dioxane molecules, lowering the coordinating ability of the oxyethylene segments to sodium cations (see later). Moreover, the catalytic activity of poly(oxyethylene) chains in R3a(13/60) is comparable to that of tri(oxyethylene) chains in $\mathbf{R 3 a}(3 / 13)$ and $\mathbf{R 3 a}(3 / 30)$, in spite of a higher $\mathbf{4}$ content in R3a(13/60) (also see the result in Figure 8).

Although no halogen-exchange reaction was observed without the oxyethylene chains in resins, $\mathbf{1 b}$ yields after a 6 h-reaction were $44,65,87$, and $85 \%$, respectively, using $0.5,1.0,1.5$, and 2.0 equiv. of $\mathrm{OEU}$ under the same conditions with $\mathbf{R} 3 \mathbf{a}(3 / 13)$. Thus, a reaction rate was enhanced with increasing OEU amount until it reached around 1.5 equiv., indicating that an amount of ionic species taken in by resins is restricted at an appropriate concentration so as to avoid electrostatic repulsion between the ionic species, especially for counteranions that are hardly solvated by the oxyethylene ligands. Figure 4 shows that a sodium cation is taken in with oligo(oxyethylene) chains more smoothly under anhydrous conditions than a potassium cation, although the potassium cation is taken in readily with poly(oxyethylene) chains to give $\mathbf{1 b}$ in a higher yield above $78 \%$ after a 7 h-reaction, as compared with a $17 \%$ yield using the tri(oxyethylene) analog.

Water molecules existing in the reaction system can dissociate $\mathrm{NaI}$ and $\mathrm{KI}$ salts to the ionic species hydrated with water molecules. Herein, it should be considered 


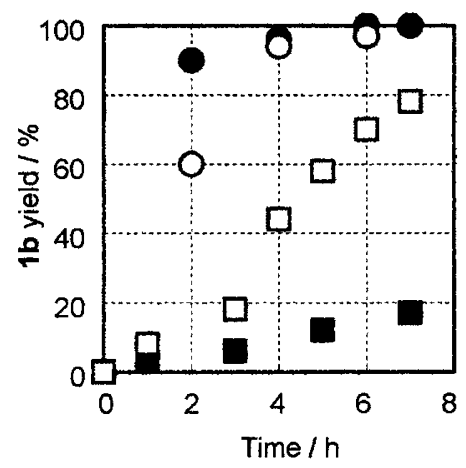

Figure 4. 1b yield-time curves for halogen-exchange reactions of 1a with 3 equiv. Nal and KI. For the reaction conditions, see those given in Figure 3. (@) NaI, R3a(3/13), ( $\bigcirc) \mathrm{NaI}, \mathbf{R 3 a}(13 / 13)$, (घ) KI, R3a(3/13); and ( $\square) \mathrm{KI}, \mathbf{R 3 a}(13 / 13)$.

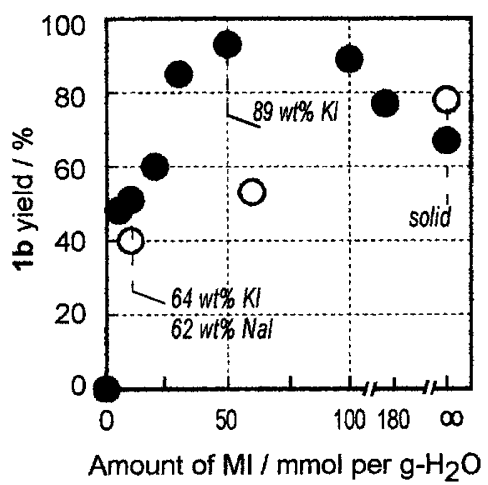

Figure 5. 1b yield after $7 \mathrm{~h}$ for halogen-exchange reactions of 1a with aqueous $\mathrm{Nal}$ and $\mathrm{KI}$ solutions using R3b(13/60). Also see reaction conditions given in Figure 3. (O) NaI and (๑) KI.

whether such dissociated (or hydrated) cations are or not complexed more smoothly with oxyethylene ligands than the cations not dissociated. In Figure 5, 1b yields after a $7 \mathrm{~h}$-reaction are compared with each other using solid $\mathrm{NaI}$ and $\mathrm{KI}$ and their $60-97 \mathrm{wt} \%$ aqueous solutions in the presence of $\mathbf{R} \mathbf{3} \mathbf{b}(13 / 60)$. The $\mathbf{1 b}$ yield attained $93 \%$ with $89 \mathrm{wt} \%$ aqueous $\mathrm{KI}$, although a series of the reactions using $\mathrm{NaI}$ gave the highest yield $78 \%$ under the anhydrous conditions.

In general, it is known that a hydrated sodium cation has a larger radius of $0.217 \mathrm{~nm}$ than a hydrated potassium cation with a $0.175 \mathrm{~nm}$ radius. ${ }^{5}$ Therefore, under hydrous conditions, the hydrated sodium cation possessing less surface charge is less favorable for cooperative coordination with the oxyethylene ligands than the hydrated potassium cation. The $\mathbf{1 b}$ yield-time curves of halogen-exchange reactions in hexane and benzene are also shown in Figure 6 to clarify the influence of organic solvents on catalytic activity of resins.

As described in the previous paper concerning halogen-exchange reactions using 12a in place of $\mathbf{1 a}$, $\mathbf{R 3 a}(3 / 13)$ had higher catalytic activity in hexane than in benzene, although tetrabutylammonium bromide (TBAB) showed a much higher reaction rate in ben-

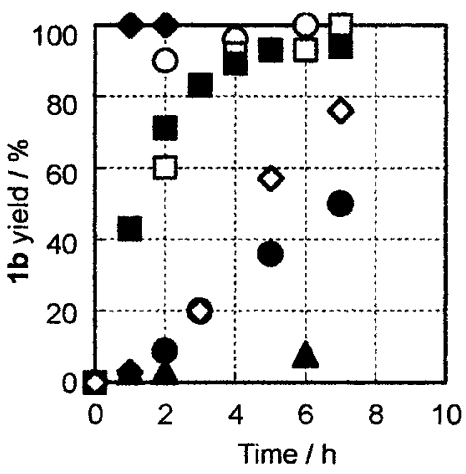

Figure 6. 1b yield-time curves for halogen-exchange reactions of 1a with Nal in hexane $(\bigcirc, \square, \diamond)$, benzene $(\boldsymbol{\bullet}, \mathbf{\square}, \diamond)$, and 1,4dioxane ( $\mathbf{\Delta})$ using $\mathbf{R 3 a}(3 / 13)(\bigcirc, \boldsymbol{O}, \mathbf{\Delta}), \mathbf{R 3 a}(13 / 60)(\square, \mathbf{\square})$, and $\operatorname{TBAB}(\diamond, \diamond)$. Also see reaction conditions given in Figure 3.

zene than in hexane. ${ }^{2}$ However, when using R3a(13/60) in the present study, the $\mathbf{1 b}$ yield-time curves for the hexane and benzene solvents were comparable to one another. This may be interpreted by a consideration that longer poly(oxyethylene) arms can catch sodium cations without solvating the arms even with benzene, since the arms are self-assembled so rigidly as to form domains, into which solvent molecules cannot interfuse, although shorter oligo(oxyethylene) arms cannot form such self-assembled domains, resulting in solvating the shorter arms easily with benzene.

Williamson-Type Etherification. In the abovementioned halogen-exchange reaction, water molecules lowered the catalytic activity of resins, although a trace amount of water favored the reaction in the case of using KI, e.g., 93 and $67 \%$ yields of $\mathbf{1 b}$ with $89 \mathrm{wt} \%$ aqueous and solid KI, respectively. To further investigate the influence of water molecules on the catalytic activity of resins, we used a $60 \mathrm{wt} \%$ aqueous $\mathrm{KOH}$ solution as a base in the Williamson-type etherification reactions of benzyl alcohol (5) and phenol (8) with butyl bromide (6). Figure 7 shows 7 yield-time curves for the reaction of 5 with $\mathbf{6}$ using $60 \mathrm{wt} \%$ aqueous $\mathrm{KOH}$ in the presence of 0.76 equiv. $\mathrm{OEU}$ of $\mathbf{R 3 a}(3 / 30)$ and $\mathbf{R 3 a}(13 / 60)$ in hexane or benzene at $35^{\circ} \mathrm{C}$.

The poly(oxyethylene) pendants of R3a(13/60) had higher catalytic activity both in hexane and in benzene than the tri(oxyethylene) analogs of R3a(3/30). Furthermore, 7 yields after a $7 \mathrm{~h}$-reaction at $35^{\circ} \mathrm{C}$ with $\mathbf{R} 3 \mathbf{b}(13 / 0)$ were $86,67,67$, and $35 \%$, respectively, in hexane, benzene, diethyl ether, and 1,4-dioxane, indicating that 1,4-dioxane was inferior to the others as a solvent upon cooperative coordination of oxyethylene ligands to a potassium cation. This may be interpreted by a consideration that the oxyethylene ligands tend to be solvated with 1,4-dioxane molecules, which resemble the structure of an oxyethylene unit, compared with the other solvents used. Figure 8 shows 9 yield-time 


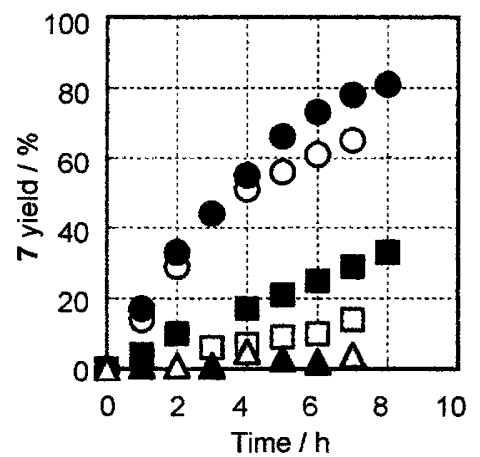

Figure 7. 7 yield-time curves for Williamson-type etherforming reactions of 5 with 3 equiv. 6 using resins (containing 0.76 equiv. OEU) with $60 \mathrm{wt} \% \mathrm{KOH}$ in hexane $(\boldsymbol{\square}, \boldsymbol{\bullet}, \boldsymbol{\Delta})$ and benzene $(\square, \bigcirc, \triangle)$ at $35^{\circ} \mathrm{C}$. Resins: $\mathbf{R 3 a}(3 / 30)(\mathbf{\square}, \square), \mathbf{R 3 a}(13 / 60)(\mathbf{\bullet}, \bigcirc)$, and without a resin $(\boldsymbol{\Lambda}, \triangle)$.

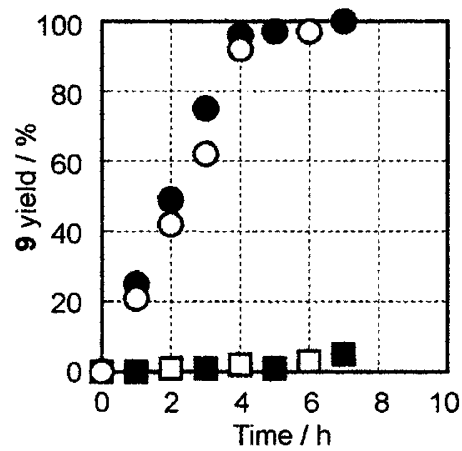

Figure 8. 9 yield-time curves for Williamson-type etherforming reactions of $\mathbf{8}$ with 3 equiv. 6 using resins (containing 0.76 equiv. OEU) with $60 \mathrm{wt} \% \mathrm{KOH}$ in hexane at $60^{\circ} \mathrm{C}$. (O) $\mathbf{R 3 b}(13 / 0)$, (@) R3b(13/30), ( $\square) \mathbf{R 3 b}(3 / 0)$, ( $\mathbf{\square}) \mathbf{R 3 b}(3 / 30)$.

curves for the Williamson-type etherification reactions of 8 with 6 using $60 \mathrm{wt} \%$ aqueous $\mathrm{KOH}$ in the presence of 0.76 equiv. OEU of $\mathbf{R} 3 \mathbf{b}(3 / l)$ and $\mathbf{R 3} \mathbf{b}(13 / l), l=0$ and 30 , in hexane at $60^{\circ} \mathrm{C}$.

Poly(oxyethylene) chains, bound in resins, $\mathbf{R} 3 \mathbf{b}(13 / 0)$ and $\mathbf{R 3} \mathbf{b}(13 / 30)$, in the form of crosslinking, showed high catalytic activity in the etherforming reactions, indicating obviously that the 4 content in $\mathbf{R 3} \mathbf{b}(13 / 0)$ and $\mathbf{R} 3 \mathbf{b}(13 / 30)$ did not affect the catalytic activity of poly(oxyethylene) chains, either. However, the corresponding tri(oxyethylene) chains of $\mathbf{R} 3 \mathbf{b}(3 / 0)$ and $\mathbf{R} 3 \mathbf{b}(3 / 30)$ hardly had such catalytic activity, being ascribed to the fact that these oxyethylene segments are close to the alkyl spacers, as described for interference by the spacer and terminal butyl groups adjacent to the oxyethylene units. ${ }^{2}$ Moreover, the poly(oxyethylene) chains used in benzene had the catalytic activity comparable to that observed in hexane. These findings indicate that the coordinating ability of poly(oxyethylene) chains are not affected even by benzene, although influenced moderately by 1,4-dioxane, possibly due to forming domains of the self-assembled poly(oxyethylene) segments.
(1)

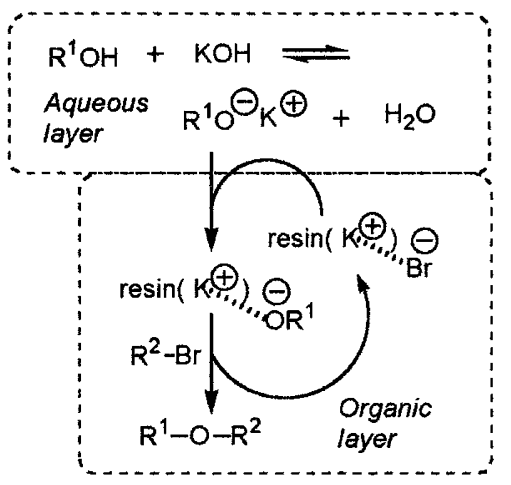

(2)

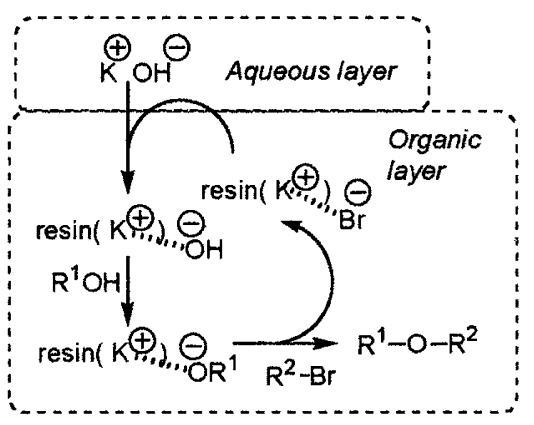

Scheme 4. Reaction mechanisms for a phase-transfer catalysis forming ethers from hydroxy compounds and alkyl bromides.

For formation of poly(oxyethylene)-complexed potassium benzyl oxide $\left(\mathrm{KOCH}_{2} \mathrm{C}_{6} \mathrm{H}_{5}\right)$ and phenoxide, two mechanisms are considered as follows: (1) these potassium salts, generated in a $60 \mathrm{wt} \%$ aqueous $\mathrm{KOH}$ layer, are taken in by poly(oxyethylene) ligands to be transferred into a resin, and (2) poly(oxyethylene)complexed $\mathrm{KOH}$ gives the potassium salts from $\mathbf{5}$ and 8 dissolved in an organic layer present in the resin (Scheme 4).

In the previous study, styrene was produced from (2-iodoethyl)benzene in a low yield of $23 \%$ using $\mathbf{R 3 a}(3 / 13)$ in $60 \mathrm{wt} \%$ aqueous $\mathrm{KOH}$ and hexane, indicating that the hydroxide counteranion, which was accompanied into an organic layer by the poly(oxyethylene)-complexed potassium cation in the same manner as shown in Mechanism (2), acted as a strong base to abstract the $\beta$-proton of (2iodoethyl)benzene existing in the organic layer in a resin. On the other hand, Mechanism (1) is supported from the following finding. When 3-methyl3-hydroxymethyloxetane was allowed to react with a 3 molar amount of 1,4-dibromobutane by phasetransfer catalyses using $\mathbf{R 3 a}(13 / 60)$ and $\mathbf{R 3} \mathbf{b}(13 / 0)$ in the $60 \mathrm{wt} \%$ aqueous $\mathrm{KOH}$ and hexane layers, 1a was detected by glpc in a range of $60-69 \%$ yield. Since 3-methyl-3-hydroxymethyloxetane is hydrophilic, this alcohol tends to dissolve in the aqueous layer rather than in the hexane layer. The corresponding alkoxide 
Table III. Elimination of $\mathbf{1 a}$ or $\mathbf{1 b}$ to $\mathbf{1 0}$ with $\mathbf{R 3 b}(13 / 60)^{\mathrm{a}}$

\begin{tabular}{cccc}
\hline Entry & Halide & Time $/ \mathbf{h}$ & $\mathbf{1 0}_{\text {yield }} / \%$ \\
\hline 1 & $\mathbf{1 a}^{\mathrm{c}}$ & 8 & 0 \\
2 & $\mathbf{1 a}$ & 10 & 7 \\
3 & $\mathbf{1 a}$ & 21 & $17^{\mathrm{d}}$ \\
4 & $\mathbf{1 b}$ & 5 & 7 \\
5 & $\mathbf{1 b}$ & 12 & 32 \\
6 & $\mathbf{1 b}$ & 15 & $36^{\mathrm{d}}$ \\
7 & $\mathbf{1 a}^{\mathrm{e}}$ & 6 & 14 \\
\hline
\end{tabular}

${ }^{\mathrm{a}} \mathbf{1 b}, 0.31 \mathrm{~g}(1.1 \mathrm{mmol}) ; 0.31 \mathrm{~g}$ (containing $3.1 \mathrm{mmol}$ OEU); $\mathrm{NaOH}, 1.28 \mathrm{~g}(32 \mathrm{mmol})$; hexane, $5 \mathrm{~cm}^{3}$; $n$ $\mathrm{C}_{14} \mathrm{H}_{30}, 0.16 \mathrm{~g}$; temp, $60{ }^{\circ} \mathrm{C}$. ${ }^{\mathrm{b}}$ Determined by glpc $\left(n-\mathrm{C}_{14} \mathrm{H}_{30}\right.$ as an internal standard). ${ }^{c}$ Without PTC. ${ }^{\mathrm{d}}$ Isolated yield. ${ }^{\mathrm{e}}$ An one-pot two-stage reaction using 1a in place of 1b. Also see the experimental section.

anion generated in the aqueous layer is caught with poly(oxyethylene) ligands in the aqueous layer or on the interface between the aqueous and organic layers, and then transferred to the organic layer. Acidic 8 may also give the ether product, 9, via Mechanism (1), although hydrophobic, neutral alcohol, $\mathbf{5}$, seems to give the ether product, 7, via Mechanism (2). Since the alkoxide counteranions are more hydrophobic than the halogen analogs, the former is not so hydrated as the latter is, when these anions are transferred to the organic layer. Therefore, the alkoxide counteranions can hold their nucleophilicity upon the etherification in the ogranic layer, even under the hydrous conditions using $60 \mathrm{wt} \% \mathrm{KOH}$. Although the hydroxide counteranion of resin-complexed $\mathrm{KOH}$ is also more or less hydrated in the organic layer, such a counteranion can act as a base with basicity higher than that of the hydroxide anion hydrated sufficiently in the aqueous layer.

Elimination of $\mathbf{1 a}$ or $\mathbf{1 b}$ to $\mathbf{1 0}$ with a Polymeric PTC. In the previous study, $\mathbf{R 3 a}(3 / 13)$ was used as a polymeric PTC for elimination reactions of (2bromoethyl)benzene, giving styrene in 9 and $0 \%$ yields, respectively, using $60 \mathrm{wt} \%$ aqueous $\mathrm{KOH}$ and $50 \mathrm{wt} \%$ aqueous $\mathrm{NaOH}$ as a base. ${ }^{2}$ In the present study, $\mathbf{R 3 b}(13 / 60)$ was examined as a polymeric PTC for elimination of halides, $\mathbf{1 a}$ and $\mathbf{1 b}$, to an alkene, $\mathbf{1 0}$, using solid $\mathrm{NaOH}$ as a base, although $\mathbf{1 0}$ was not formed when $50 \mathrm{wt} \% \mathrm{NaOH}$ was used. The results for the elimination reaction are shown in Table III.

Thus, $\mathbf{1 0}$ was given from iodide, $\mathbf{1 b}$, in $36 \%$ yield after $15 \mathrm{~h}$ at $60^{\circ} \mathrm{C}$ and in $17 \%$ yield after $21 \mathrm{~h}$ even from bromide, 1a (Entry 6 and 3). Yields of $\mathbf{1 0}$ and remainders of $\mathbf{1 b}$ are plotted towards time for data of Entry 5, as shown in Figure 9, where $\mathbf{1 0}$ is detected in 32\% yield after $12 \mathrm{~h}$, whereas $\mathbf{1 b}$ is hardly left after the same reaction time. The pot residue of this reaction was analyzed by ${ }^{1}$ H NMR spectroscopy and, consequently, identified to a bisoxetane, $\mathbf{1 5}$, formed by phase-transfer catalysis

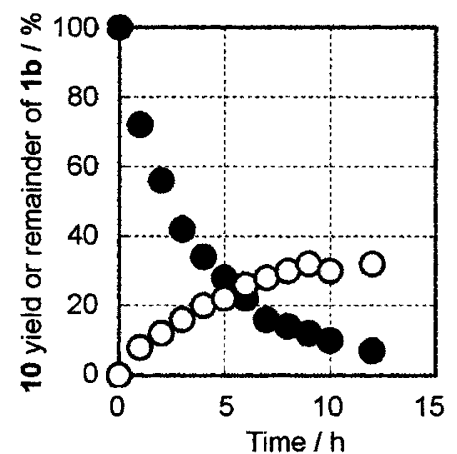

Figure 9. 10 yield- and remainder of $\mathbf{1 b}$-time curves for elimination reaction of $\mathbf{1 b}$ to $\mathbf{1 0}$ using $\mathbf{R} 3 \mathbf{b}$ (13/60) (containing 3.0 equiv. OEU) in hexane at $60^{\circ} \mathrm{C}$ with 29 equiv. solid $\mathrm{NaOH}$. (○) $\mathbf{1 0}$ and (O) $\mathbf{1 b}$.

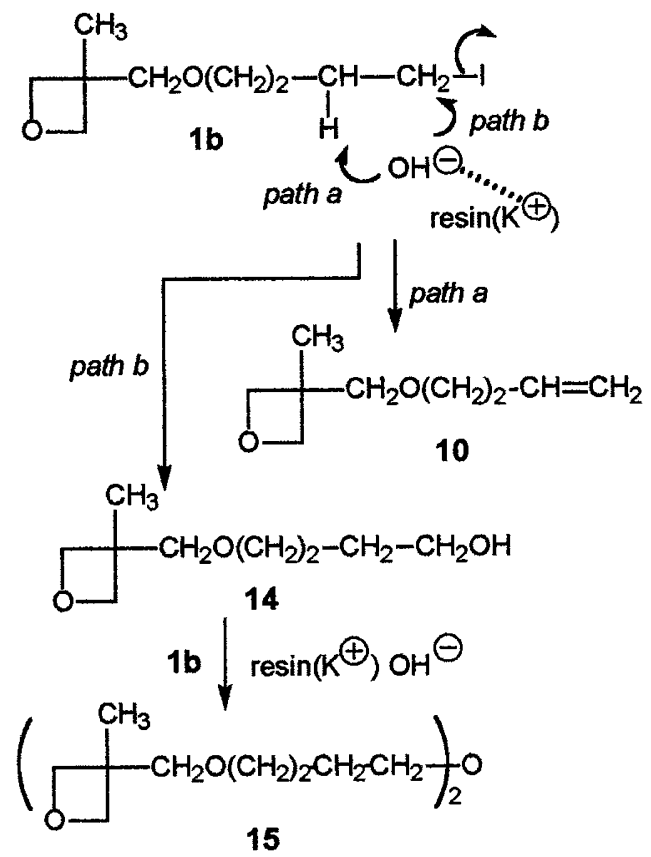

Scheme 5. A mechanism for forming alkene, 10, and ether, 15, from $\mathbf{1 b}$ with $\mathrm{KOH}$ in the presence of a polyoxetane-polyoxirane resin.

of $\mathbf{1 b}$ with an alcoholic intermediate, $\mathbf{1 4}$, which may be derived from another molecule of $\mathbf{1 b}$ by nucleophilic substitution with a hydroxide counteranion, as shown through a path $b$ in Scheme 5 .

From these findings it is suggested that the hydroxide counteranion of poly(oxyethylene)-complexed $\mathrm{NaOH}$ could act not only as a base but also as a nucleophile producing an alcohol.

C-Alkylation Reactions of Diethyl Malonate (11) with Alkyl Halides Using PTC Resins. The results are shown in Table IV.

Octylmalonic acid (13a), but not the ester, was isolated in $21 \%$ yield from the resultant mixture of a reaction of $\mathbf{1 1}$ with $\mathbf{1 2 b}$ using $\mathbf{R 3 b}(13 / 0)$ with $50 \%$ aqueous $\mathrm{NaOH}$ in hexane at $35^{\circ} \mathrm{C}$ for $2 \mathrm{~h}$ (Entry 2), although no $\mathrm{C}$-alkylation products were obtained with- 
Polyoxetane Resins Carrying Polyoxiranes

Table IV. C-alkylation of $\mathbf{1 1}$ with $\mathbf{1 2 b}$ in the presence of $\mathbf{R 3 b}(13 / l)^{\mathrm{a}}$

\begin{tabular}{|c|c|c|c|c|c|c|c|}
\hline \multirow{2}{*}{ Entry } & \multirow{2}{*}{ Resin } & \multirow{2}{*}{ Base } & \multirow{2}{*}{$\frac{\text { Hexane }}{\mathrm{cm}^{3}}$} & \multirow{2}{*}{$\frac{\text { Temp }}{\frac{{ }^{\circ} \mathrm{C}}{}}$} & \multirow{2}{*}{$\frac{\text { Time }}{\mathrm{h}}$} & \multicolumn{2}{|c|}{ Yield $^{\mathrm{b}} / \%$} \\
\hline & & & & & & $\overline{13 a}$ & $13 b$ \\
\hline 1 & None & $50 \% \mathrm{NaOH}$ & 3 & 35 & 2 & 0 & 0 \\
\hline 2 & $\mathbf{R 3 b}(13 / 0)$ & $50 \% \mathrm{NaOH}$ & 3 & 35 & 2 & 21 & 0 \\
\hline 3 & $\mathbf{R 3 b}(13 / 0)$ & $50 \% \mathrm{NaOH}$ & 10 & 35 & 2 & 12 & 0 \\
\hline 4 & $\mathbf{R} 3 \mathbf{b}(13 / 30)$ & $50 \% \mathrm{NaOH}$ & 10 & 15 & 4 & 4 & 0 \\
\hline 5 & None & solid $\mathrm{KOH}$ & 18 & 60 & 3.5 & 0 & 0 \\
\hline 6 & $\mathbf{R} 3 \mathbf{b}(13 / 30)$ & $60 \% \mathrm{KOH}$ & 3 & 35 & 2 & 3 & 0 \\
\hline 7 & $\mathbf{R} 3 \mathbf{b}(13 / 60)$ & solid $\mathrm{KOH}$ & 18 & 60 & 3.5 & 12 & 54 \\
\hline 8 & $\mathbf{R} 3 \mathbf{b}(13 / 60)^{\mathrm{c}}$ & solid $\mathrm{KOH}$ & 5 & 60 & 3.5 & 0 & $>98^{\mathrm{d}}$ \\
\hline
\end{tabular}

a 11, $1.4 \mathrm{mmol}$; 12b, $2.9 \mathrm{mmol}$; OEU, $4.7 \mathrm{mmol}$; base, $89 \mathrm{mmol}$. ${ }^{\mathrm{b}}$ Determined from the total weight and ${ }^{1} \mathrm{H}$ NMR spectrum of a product mixture separated. ${ }^{\mathrm{c}} \mathbf{1 1}, 2.3 \mathrm{mmol}$; benzyl chloride, $4.5 \mathrm{mmol}$; OEU, $2.5 \mathrm{mmol}$; base $90 \mathrm{mmol}$. ${ }^{\mathrm{d}}$ Diethyl dibenzylmalonate.

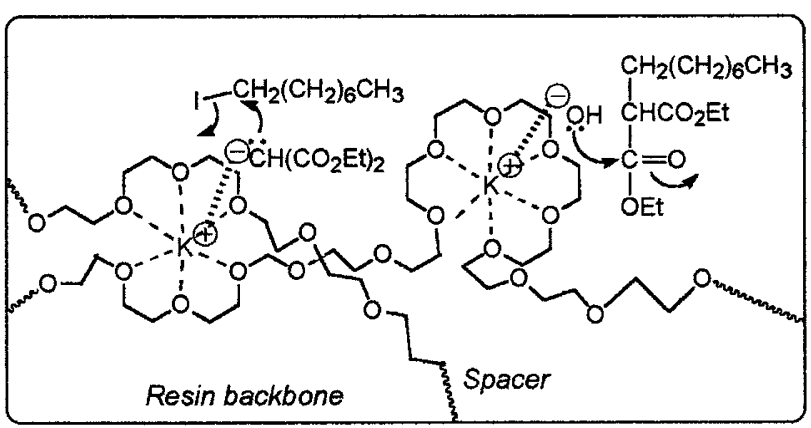

Scheme 6. Schematic diagram for interpreting C-alkylation of 11 with 12b with polyoxetane resins having oxyethylene units in the pendant and cross-linking chains.

out resin under the same reaction conditions (Entry 1 and 5). The 13a yield was decreased to $12 \%$ yield by lowering reactant concentrations (Entry 3) and further to $4 \%$ yield both by increasing the 4 unit to $30 \mathrm{~mol} \%$, i.e., with $\mathbf{R} 3 \mathbf{b}(13 / 30)$, and by lowering reaction temperature to $15^{\circ} \mathrm{C}$ (Entry 4). Moreover, when the same resin, $\mathbf{R 3 b}(13 / 30)$, was used with $60 \%$ aqueous $\mathrm{KOH}$, only $3 \%$ yield of 13a was observed in spite of raising temperature and reactant concentration from those in Entry 4 (Entry 6). However, when R3b(13/60) was used with solid $\mathrm{KOH}$ at $60^{\circ} \mathrm{C}$, both 13a and dioctylmalonic acid (13b) were obtained in 12 and 54 yields, respectively, even at lowered reactant concentrations (Entry 7). Thus, the product yield is influenced by such factors as reaction temperature, reactant concentration, base, and degree of cross-linking. Among these factors the temperature seems the most important. The soft polyether network of the resin becomes so expanded at higher temperature as to smoothly take in both ionic species and 12b into the reaction stage formed in the resin, as illustrated in Scheme 6.

However, malonic acid gave no products under these reaction conditions, indicating that the potassium enolates generated from esters, $\mathbf{1 1}$ and its C-octylsubstituted derivative, are allowed to react with $\mathbf{1 2 b}$ very rapidly upon the $\mathrm{C}$-alkylation before alkaline hy- drolysis of the esters. Bromide, 12a, used in place of the iodide, 12b, did not give any product, due to the fact that the bromine atom is a leaving group inferior to the iodine atom. In Entry 8, when benzyl chloride was used as an alkyl halide, diethyl dibenzylmalonate was obtained in the nearly quantitative yield. This result is ascribed to considerations that benzyl chloride is a highly reactive substrate as well as that the benzylsubstituted malonates are unsusceptible to alkaline hydrolysis due to the steric hindrance and hydrophobicity of the benzyl moiety.

In conclusion, polyoxetane resins with the pendant and cross-linked poly(oxyethylene) chains were prepared by ring-opening polymerization of the oxetane moieties and used well as polymeric solvents for alkalimetal ions, as shown by using the resins as a PTC in several organic reactions.

Several types of insoluble polyoxirane-bearing resins have already been examined in phase-transfer catalysis. Especially, pendant polyoxirane chains are used conveniently as a PTC by immobilizing to divinylbenzene (DVB)-cross-linked polystyrenes, which have been widely used as a supporting matrix. ${ }^{6-11}$ In the halogen-exchange reaction, the catalytic activity of the pendant tri(oxyetylene) chains anchored to a $17 \%$ DVB-cross-linked polystyrene was somewhat inferior to that of the analogous pendants of R3a(3/13) and the polystyrene resin was brittle, as suggested from the observation that the resin was ground to powder during agitation with a stirring bar. ${ }^{2}$ However, the pendant penta(oxyethylene) chains immobilized to $1-2 \%$ DVB-cross-linked polystyrenes indicated higher phasetransfer catalytic activity upon nucleophilic substitution of $\mathbf{6}$ with anhydrous sodium phenoxide in refluxing toluene. ${ }^{6}$ In the same reaction in water beside toluene solvents, the pendant poly(oxyethylene) chains immobilized to cross-linked polymethacrylate resins also formed $\mathbf{7}$ at higher relative rates compared with those of the poly(oxyethylene)s not immobilized to the poly- 
mer matrices. ${ }^{12}$ When 2-bromooctane was heated with $60 \mathrm{wt} \%$ aqueous $\mathrm{KOH}$ in the presence of polystyrenelinked oxyethylene segments in hexane at $70{ }^{\circ} \mathrm{C}$, a mixture of 1 - and 2-octenes was formed in $82 \%$ yield, but not 2-octanol, ${ }^{3}$ although, in this work, a polyoxiranepolyoxetane composite resin gave the alcoholic intermediate, $\mathbf{1 4}$, from the iodide, $\mathbf{1 b}$, with solid $\mathrm{NaOH}$. The C-alkylation reaction system using polyoxiranepolyoxetane composite resins has not yet investigated, to our knowledge, whereas C-alkylated malonic esters were given from $\mathbf{1 1}$ with shorter alkyl halides in good yield by the ordinary phase-transfer catalysis with tetrabutylammonium hydrogen sulfate in the DCM organic and $7 \mathrm{wt} \% \mathrm{NaOH}$ aqueous layers. ${ }^{13}$

Furthermore, the PTC resins used in this work could catch not only sodium cations but also potassium cations smoothly and showed catalytic activities comparable to each other in hexane and benzene solvents, although potassium cation and benzene were not effective as an ionic species or a solvent under the conditions using the analogous resins with olig(oxyethylene) pendants, suggesting that the poly(oxyethylene) chains supported by polyoxetane backbones had a structure different from those of the analogous oligo(oxyethylene) chains. The poly(oxyethylene) chains may have a tendency to selfassemble, as known in general for crystallized polyoxirane. ${ }^{14}$ Such self-assembled poly(oxyethylene) segments, which are formed in hydrophobic cross-linked polyoxetane matrices, prevent even good solvents, such as benzene and water, from interfusing thoroughly into the poly(oxyethylene) segments. Moreover, elastic polyoxetane matrices may play an important role in giving domains, which can take in the reaction species, by relaxing attractive interaction forces in some parts of the self-assembled poly(oxyethylene) segments. Additionally, the PTC resins could be used in the present phase-transfer catalyses repeatedly at least four or five times after ready recovery by filtration from the reaction mixture. Thus, the polyoxirane-polyoxetane composite resins being soft, not brittle, and alkali-resistant are regarded as polymeric media with ion-affinity and -transferring ability in the manner of cooperative coordination with oxyethylene units.

\section{EXPERIMENTAL}

\section{Materials}

Monomers, $3 \boldsymbol{a}(13), 3 \boldsymbol{b}(3)$, and $\mathbf{3 b}(13)$. The preparation of $3 \mathbf{b}(13)$ is described for the typical procedure, as follows: in a $50 \mathrm{~cm}^{3}$ round-bottomed flask equipped with a reflux condenser and a stirring bar, were placed 1a $(5.0 \mathrm{~g}, 21.0 \mathrm{mmol})$, polyethylene glycol $600(5.0 \mathrm{~g})$, TBAB $(0.26 \mathrm{~g}, 0.81 \mathrm{mmol}), 60 \mathrm{wt} \%$ aqueous $\mathrm{KOH}(22.0 \mathrm{~g})$, and hexane $\left(17 \mathrm{~cm}^{3}\right)$. The contents were stirred at the refluxing temperature for $15 \mathrm{~h}$. Water $\left(17 \mathrm{~cm}^{3}\right)$ was added to the reaction mixture, cooled by an ice-bath, and extracted with ether. By evaporating the ether layer $5.1 \mathrm{~g}$ (about $67 \%$ yield) of $\mathbf{3 b}(13)$ was left as a pot residue: IR (neat) 1110 (acyclic ether) and 980 and $838 \mathrm{~cm}^{-1}$ (cyclic ether); ${ }^{1} \mathrm{H}$ NMR $\left(\mathrm{CDCl}_{3}\right) \delta=1.30\left(s, 6 \mathrm{H}, \mathrm{CH}_{3}\right), 1.6-1.7[\mathrm{~m}$, $8 \mathrm{H},-\mathrm{OCH}_{2}\left(\mathrm{CH}_{2}\right)_{2} \mathrm{CH}_{2} \mathrm{O}-$ ], 3.4-3.7 [64H: $s$ and $m$, $\left.-\mathrm{C}_{2} \mathrm{OCH}_{2}\left(\overline{\mathrm{CH}}_{2}\right)_{2} \mathrm{C}_{2} \mathrm{O}\left(\mathrm{C}_{2} \mathrm{CH}_{2} \mathrm{O}\right)_{13}-\right]$, and 4.43 and $4.50\left(\mathrm{AB}-q\right.$, each $4 \mathrm{H}, J=6.0 \mathrm{~Hz}, \mathrm{CH}_{2}$ of the oxetane ring).

3a(13): about 51\% yield; IR (neat) 1110 (acyclic ether) and 980 and $838 \mathrm{~cm}^{-1}$ (cyclic ether); ${ }^{1} \mathrm{H}$ NMR $\left(\mathrm{CDCl}_{3}\right) \delta=1.30 \quad\left(s, 6 \mathrm{H}, \mathrm{CH}_{3}\right), \quad 1.6-1.7 \quad[m$, $\left.8 \mathrm{H},-\mathrm{OCH}_{2}\left(\mathrm{CH}_{2}\right)_{2} \mathrm{CH}_{2} \mathrm{O}-\right], \quad 3.4-3.7 \quad[57 \mathrm{H}: s$ and $\left.m,-\underline{\mathrm{C}}_{2} \mathrm{OC}_{2} \underline{\mathrm{H}}_{2}\left(\mathrm{CH}_{2}\right)_{2} \underline{\mathrm{C}}_{2} \mathrm{O}\left(\mathrm{C}_{2} \mathrm{C}_{2} \mathrm{O}\right)_{13} \mathrm{OCH}_{3}\right]$, and 4.34 and $4.50\left(\mathrm{AB}-q\right.$, each $4 \mathrm{H}, J=6.0 \mathrm{~Hz}, \mathrm{CH}_{2}$ of the oxetane ring).

3b(3): about $80 \%$ yield; IR (neat) 1110 (acyclic ether) and 980 and $838 \mathrm{~cm}^{-1}$ (cyclic ether); ${ }^{1} \mathrm{H}$ NMR $\left(\mathrm{CDCl}_{3}\right) \delta=1.30\left(\mathrm{~s}, 6 \mathrm{H}, \mathrm{CH}_{3}\right), 1.6-1.7[\mathrm{~m}, 8 \mathrm{H}$, $-\mathrm{OCH}_{2}\left(\mathrm{CH}_{2}\right)_{2} \mathrm{CH}_{2} \mathrm{O}-$ ], 3.4-3.7 [24H: $s$ and $m$, $\left.\mathrm{C}_{2} \mathrm{OC}_{2}\left(\mathrm{CH}_{2}\right)_{2} \underline{\mathrm{C}}_{2} \mathrm{O}\left(\underline{\mathrm{C}}_{2} \underline{\mathrm{C}}_{2} \mathrm{O}\right)_{3}-\right]$, and 4.34 and $4.50\left(\mathrm{AB}-q\right.$, each $4 \mathrm{H}, J=5.6 \mathrm{~Hz}, \mathrm{CH}_{2}$ of the oxetane ring).

3a(2) and 3a(3) were obtained according to the method reported in literature. ${ }^{2}$

3-(4-Iodobutoxymethyl)-3-methyloxetane (1b). Obtained in $90 \%$ yield by heating the corresponding bromide, 1a, $(5.0 \mathrm{~g}, 21 \mathrm{mmol})$ with $\mathrm{KI}(35.0 \mathrm{~g}, 0.21 \mathrm{~mol})$ in acetone $\left(50 \mathrm{~cm}^{3}\right)$ at the refluxing temperature for $24 \mathrm{~h}$, followed by post-treating the reaction mixture in the ordinary way: bp $71-73^{\circ} \mathrm{C}(0.24-0.28 \mathrm{~Pa})$; IR (neat) 1115 (acyclic ether) and 980 and $835 \mathrm{~cm}^{-1}$ (cyclic ether); ${ }^{1} \mathrm{H}$ NMR $\left(\mathrm{CDCl}_{3}\right) \delta=1.31\left(\mathrm{~s}, 3 \mathrm{H}, \mathrm{CH}_{3}\right)$, 1.6-1.7 [m, 2H, $\left.\mathrm{O}\left(\mathrm{CH}_{2}\right)_{2} \mathrm{CH}_{2} \mathrm{CH}_{2} \mathrm{I}\right], 1.8-1.9[\mathrm{~m}, 2 \mathrm{H}$, $\left.\mathrm{OCH}_{2} \underline{\mathrm{CH}}_{2}\left(\mathrm{CH}_{2}\right)_{2} \mathrm{I}\right], 3.23\left[t, 2 \mathrm{H}, J=6.8 \mathrm{~Hz}, \mathrm{O}\left(\mathrm{CH}_{2}\right)_{3}\right.$ $\left.\mathrm{C}_{2} \mathrm{I}\right], 3.42-3.58$ [4H: $\delta=3.47\left(s, \mathrm{CH}_{2} \mathrm{O}\left(\mathrm{CH}_{2}\right)_{4} \mathrm{I}\right) ; \delta=$ $\left.3.50\left(t, J=6.2 \mathrm{~Hz}, \mathrm{CH}_{2} \mathrm{O} \mathrm{C} \underline{H}_{2}\left(\mathrm{CH}_{2}\right)_{3} \mathrm{I}\right)\right]$, and 4.36 and 4.50 (each $2 \mathrm{H}, \mathrm{AB}-q, J=5.7 \mathrm{~Hz}, \mathrm{CH}_{2}$ of the oxetane ring).

3-(3-Butenyloxymethyl)-3-methyloxetane (10). Obtained in $36 \%$ yield by stirring $1 \mathrm{~b}(1.21 \mathrm{~g}, 4.24 \mathrm{mmol})$ in hexane $\left(14 \mathrm{~cm}^{3}\right)$ with $\mathrm{NaOH}(4.73 \mathrm{~g}, 0.12 \mathrm{~mol})$ in the presence of $\mathbf{R} 3 \mathbf{b}(13 / 60)$ (1.28 g, $12.96 \mathrm{mmol}$ OEU) at $60^{\circ} \mathrm{C}$ for $15 \mathrm{~h}$, followed by post-treating the resultant mixture in the ordinary way: bp $32-35^{\circ} \mathrm{C}(8-$ $11 \mathrm{~Pa})$; IR(neat) $1640\left(v_{C=C}\right)$ and 980 and $840 \mathrm{~cm}^{-1}$ (cyclic ether); ${ }^{1} \mathrm{HNMR}\left(\mathrm{CDCl}_{3}\right) \delta=1.31\left(s, 3 \mathrm{H}, \mathrm{CH}_{3}\right)$, $2.35\left(m, 2 \mathrm{H},-\underline{\mathrm{C}}_{2} \mathrm{CH}=\mathrm{CH}_{2}\right), 3.49-3.53(4 \mathrm{H}: s$ and 
$\left.t, \mathrm{CH}_{2} \mathrm{OCH}_{2} \mathrm{CH}_{2} \mathrm{CH}=\mathrm{CH}_{2}\right), 4.35$ and $4.51($ each $2 \mathrm{H}$, AB-q, $J=6.0 \mathrm{~Hz}, \mathrm{CH}_{2}$ of the oxetane ring), 4.99-5.16 $\left(2 \mathrm{H}, m,-\mathrm{CH}=\underline{\mathrm{C}}_{2}\right)$, and $5.64-5.98(1 \mathrm{H}, m,-\underline{\mathrm{C}}=$ $\mathrm{CH}_{2}$ ).

Diethyl Dibenzylmalonate and Octyl- and Dioctylmalonic Acids (13a and 13b). Diethyl dibenzylmalonate was prepared according to literature. ${ }^{15,16}$ The malonic acids were obtained by alkaline hydrolysis of the corresponding diethyl esters $(3.8 \mathrm{mmol})$ with $\mathrm{NaOH}$ $(2.1 \mathrm{~g})$ in refluxing ethanol $\left(15 \mathrm{~cm}^{3}\right)$ for $2 \mathrm{~h}$.

13a: $85 \%$ yield; $\mathrm{mp} 113-116^{\circ} \mathrm{C}$ (chloroformhexane); IR ( $\mathrm{KBr}$ disk) 3300-2500 $\left(v_{\mathrm{OH}}\right)$ and 1700$1680 \mathrm{~cm}^{-1}\left(v_{C=O}\right) ;{ }^{1} \mathrm{HNMR}\left(\mathrm{CDCl}_{3}\right) \delta=0.88(t$, $\left.3 \mathrm{H}, J=7.3 \mathrm{~Hz}, \mathrm{CH}_{3}\right), 1.14-1.26\left[\mathrm{~m}, 12 \mathrm{H},-\mathrm{CH}_{2}\right.$ $\left.\left(\mathrm{C}_{2}\right)_{6} \mathrm{CH}_{3}\right], 1.78-1.93\left[\mathrm{~m}, 2 \mathrm{H},-\mathrm{C}_{2}\left(\mathrm{CH}_{2}\right)_{6} \mathrm{CH}_{3}\right]$, and $3.51(t, 2 \mathrm{H}, J=7.3 \mathrm{~Hz}, \mathrm{CH})$.

13b: $75 \%$ yield; mp $75-77^{\circ} \mathrm{C}$ (chloroform); IR ( $\mathrm{KBr}$ disk) 3300-2500 $\left(v_{\mathrm{OH}}\right)$ and $1700-1680 \mathrm{~cm}^{-1}\left(v_{\mathrm{C}=O}\right)$; ${ }^{1} \mathrm{HNMR}\left(\mathrm{CDCl}_{3}\right) \delta=0.88\left(t, 6 \mathrm{H}, J=7.3 \mathrm{~Hz}, \mathrm{CH}_{3}\right)$, 1.14-1.26 [m, 24H, $\left.-\mathrm{CH}_{2}\left(\mathrm{C}_{2}\right)_{6} \mathrm{CH}_{3}\right], 1.78-1.93[\mathrm{~m}$, $\left.4 \mathrm{H},-\mathrm{CH}_{2}\left(\mathrm{CH}_{2}\right)_{6} \mathrm{CH}_{3}\right]$.

Other reagents and solvents were obtained as commercial chemicals and used without further purification.

\section{Polymerization}

The oxyethylene segment-containing oxetane monomers were polymerized with $\mathbf{4}$ or without it in DCM at $0{ }^{\circ} \mathrm{C}$ for $50 \mathrm{~h}$ with 0.03 equiv. of $\mathrm{BF}_{3} \mathrm{OEt}_{2}$ to the total amount of the oxetane ring to produce resins, R3a $(2$, 3 , or $13 / l)$ and $\mathbf{R} 3 \mathbf{b}(3$ or $13 / l)$, which were collected by filtration, washed with $20 \%$ aqueous methanol, and dried in vacuum to use as a PTC.

\section{Phase-Transfer Catalyses Using Resins}

The Halogen-Exchange, Ether-Forming, and Elimination Reactions. A typical procedure is described for the halogen-exchange reaction, as follows: in a $50 \mathrm{~cm}^{3}$ round-bottomed flask equipped with a reflux condenser and a stirring bar, $\mathbf{R} 3 \mathbf{b}(13 / 60)(0.15 \mathrm{~g}$, containing $1.5 \mathrm{mmol}$ of OEU), $\mathbf{1 a}(0.26 \mathrm{~g}, 1.1 \mathrm{mmol})$, tetradecane $(0.16 \mathrm{~g})$, NaI $(0.50 \mathrm{~g}, 3.3 \mathrm{mmol})$, and hexane $\left(5 \mathrm{~cm}^{3}\right)$ were placed. The contents were stirred at $60^{\circ} \mathrm{C}$, and aliquots were withdrawn with a syringe after appropriate reaction times to determine the $\mathbf{1 b}$ yield by glpc using tetradecane as an internal standard and a $4 \phi \times 1500 \mathrm{~mm}$ column packed with Silicone HV grease (30\%) on Kamelite CK (80-100 mesh).

The one-pot two-stage reaction using 1a in place of 1b was effected as follows: 1a $(0.26 \mathrm{~g}, 1.1 \mathrm{mmol})$ was converted to $\mathbf{1 b}$ by the same way as above-mentioned, although $0.31 \mathrm{~g}$ ( $3.1 \mathrm{mmol} \mathrm{OEU})$ of $\mathbf{R 3} \mathbf{b}(13 / 60)$ was used, and subsequently stirred with solid $\mathrm{NaOH}(1.1 \mathrm{~g}$, $28 \mathrm{mmol}$ ), added directly into the reactor, at $60^{\circ} \mathrm{C}$ for additional $6 \mathrm{~h}$. The resultant mixture was post-treated similarly.

C-alkylation of 11 with Alkyl Halides. A typical procedure is as follows: in a $50 \mathrm{~cm}^{3}$ round-bottomed flask equipped with a reflux condenser and a stirring bar, R3b(13/60) (0.46 g, containing $4.7 \mathrm{mmol} \mathrm{OEU})$, $\mathbf{1 1}(0.23 \mathrm{~g}, 1.44 \mathrm{mmol}), \mathbf{1 2 b}(0.70 \mathrm{~g}, 2.91 \mathrm{mmol}), \mathrm{KOH}$ $(5.0 \mathrm{~g}, 89 \mathrm{mmol})$, and hexane $\left(5 \mathrm{~cm}^{3}\right)$ were placed. The contents were stirred at $60^{\circ} \mathrm{C}$ for $3.5 \mathrm{~h}$ and then cooled in an ice bath to be acidified with concentrated $\mathrm{HCl}$ at $\mathrm{pH}$ 4. The resin was removed by filtration and the filtrate was extracted with ether. After the ether layer was evaporated, the residue was recrystallized from chloroform-hexane and the resulting white solid was subjected to ${ }^{1} \mathrm{H}$ NMR analysis to determine a 13a:13b molar ratio.

\section{REFERENCES}

1. a) M. Motoi, Polym. Appl. (Kobunshi Kako), 39, 59 (1990). b) M. Motoi, Polym. Appl. (Kobunshi Kako), 44, 12 (1995).

2. A. Ueyama, M. Mizuno, H. Ogawa, S. Kanoh, and M. Motoi, Polym. J., 33, 754 (2001).

3. Y. Kimura and S. L. Regen, J. Org. Chem., 48, 195 (1983).

4. Y. Miwa, H. Tsutsumi, and T. Oishi, Polym. J., 33, 568 (2001).

5. R. Matsuura "Gendai Mukikagaku Koza," Gihoudo Co. Ltd., Tokyo, 1971, vol. 7, p 126.

6. S. L. Regen and L. Dulak, J. Am. Chem. Soc., 99, 623 (1977).

7. W. M. MacKenzie and D. C. Sherrington, Chem. Commun., 541 (1978).

8. W. M. MacKenzie and D. C. Sherrington, Polymer, 21, 791 (1980).

9. Y. Kimura, P. Kirszensztejn, and S. L. Regen, J. Org. Chem., 48, 385 (1983).

10. M. Tomoi, T. Suzuki, and H. Kakiuchi, React. Polym., 10, 27 (1989).

11. M. L. Hallensleben and F. Lucarelli, Polym. Bull., 37, 759 (1996).

12. J. Hradil and F. Švec, Polym. Bull., 11, 159 (1984).

13. A. Brändström and U. Junggren, Tetrahedron Lett., 475 (1972).

14. Y. Takahashi and H. Tadokoro, Macromolecules, 6, 672 (1973).

15. L. Schleich, Chem. Ber., 20, 439 (1987).

16. M. Motoi, H. Suda, M. Kijima, T. Doi, T. Nakagawa, and S. Kanoh, Polym. J., 21, 451 (1989). 